\title{
The Importance of Genetic Testing in the Clinical Management of Patients with Marfan Syndrome and Related Disorders
}

\author{
Mine Arslan-Kirchner, Yskert von Kodolitsch, Jörg Schmidtke
}

\begin{abstract}
SUMMARY
Introduction: Marfan syndrome and Marfan-related syndromes are part of a broad and overlapping spectrum of diseases that were originally defined on clinical grounds alone. They have in common a dramatically increased risk of life-threatening dissecting aortic aneurysms, which must be prevented by elective aortic replacement.

Methods: Selective review of the literature supplemented by own clinical experience.

Results: Marfan syndrome and Marfan-related syndromes are phenotypically highly variable. The full-blown clinical picture is not always present, and particular symptoms can be missing altogether. Accordingly, it is often very difficult to diagnose a specific syndrome in the individual patient. In many cases, only a combination of genetic tests and clinical assessment can settle the differential diagnosis, thus enabling better prognostication and better planning of preventive measures.
\end{abstract}

Discussion: The diagnosis and treatment of individual patients with Marfan syndrome and Marfan-related syndromes requires an interdisciplinary approach. This can only be achieved through a coordination of medical care with centralized record-keeping of all diagnostic findings.

Dtsch Arztebl Int 2008; 105(27): 483-91 DOI: 10.3238/arztebl.2008.0483

Key words: Marfan syndrome, molecular medicine, genetic testing, aneurysm, aortic syndrome, mitral valve prolaps

Institut für Humangenetik, Medizinische Hochschule Hannover, Carl-NeubergStr. 1, 30625 Hannover: Prof. Dr. med. Schmidtke, PD Dr. med. Arslan-Kirchner

Klinik und Poliklinik für Kardiologie/Angiologie, Universitätsklinikum HamburgEppendorf: PD Dr. med. von Kodolitsch $\mathrm{n}$ the course of the human genome project, the human genome has largely been decoded. This has benefited genetic reproductive counseling. Moreover, the new genetic knowledge can now be applied in clinical practice, as part of the so-called genetic medicine (1). The clinical management of many diseases has been improved by the specific incorporation of genetic testing procedures. If specific genetic risks can be determined, the prognosis for the individual patient can be estimated more exactly. This allows preventive measures adapted to the individual patient and influences the therapeutic procedure. Conversely, if a disease or susceptibility to a disease can be specifically excluded, this can spare the patient the differential diagnostic procedures and the preventive measures, together with the stress which results from these. The Marfan syndrome and related diseases can serve as an example of the clinical benefit of genetics.

The Marfan-related syndromes are part of a broad spectrum of related diseases, which were originally defined on clinical grounds alone. They have in common a dramatically increased risk of potentially fatal acute aortic syndrome (AAS) (2), i.e., dissecting aneurysm of the thoracic aorta, which must be prevented by elective replacement of the damaged aorta. The pattern of symptoms varies greatly between patients, as the fullblown clinical picture is not always present and particular symptoms may be missing. It is often very difficult to classify a patient to a specific syndrome. There may even be extreme differences in the presentation within a single family. If very strict criteria are taken for the clinical diagnosis, many patients cannot be diagnosed. On the other hand, if the diagnostic criteria are too broad, there are many false positives. Both of these errors may have serious consequences, if the treatment or secondary preventive measures depend on the correct diagnosis. In such cases, genetic testing can make things clear. The diagnosis can be made before the symptoms have (fully) developed and the type of genetic change is often a prognostic factor in itself.

The Marfan-related syndromes are an example of allelic and locus heterogeneity. Mutations in a single gene 


\section{BOX 1}

\section{Case}

Gert L., aged 31, and his sister-in-law Renate present for genetic counseling. When Gert was aged 23, a cardiologist suspected that he had the Marfan syndrome on the basis of the clinical symptoms. He reported this to the family GP, but not to Gert himself. When Gert was 27, his aorta had dilated to such an extent, that there was an indication for prophylactic surgery.

The operation was successful. However, Gert was provided with no information about his suspected Marfan syndrome; all information he was given was focused on the aorta disease. Gert's brother Kai was tall and thin, but had no subjective symptoms of disease. He was a serious sportsman (basketball). Their mother had suddenly died at the age of 36 . Her children only knew that she had had a heart defect. The reason they were seeking advice was that Kai had suddenly died a few weeks previously, at the age of 29. He had collapsed during a game of basketball and a postmortem had found a dissecting aortic aneurysm. The significance of the suspected diagnosis of Marfan syndrome made years previously suddenly became clear to the whole family and to the GP. The GP had not understood that, although the medical care was optimal for Gert, it was not enough for the whole family. After the suspected diagnosis of Marfan syndrome, it would have been necessary to explain the hereditary character of this condition to all members of the family and Kai should have been investigated, both clinically and possibly genetically. His four-year-old daughter Melanie is still clinically more or less normal, but unusually tall. Genetic testing established that she bears the gene for the Marfan syndrome. She is being given regular clinical examinations.

\section{Marfan-related syndromes: clinical symptoms and genetics}

All clinical entities discussed below are heritable in an autosomal-dominant fashion.

\section{Marfan syndrome type 1}

The classical Marfan syndrome (MFS1, OMIM 154700) (OMIM, "Online Mendelian Inheritance in Man"; www.ncbi.nlm.nih.gov/omim) is a systemic disease of connective tissue. MFS1 is caused by mutations in the fibrillin-1 gene $(F B N 1)$ on chromosome 15q21.1. All organ systems may be affected, but particularly the skeleton, the eye and the cardiovascular system (table 1). Although there are rare cases of very severely affected neonates, the symptoms normally develop during the first two decades of life. It is often difficult to decide on the basis of the clinical symptoms alone whether a child or adolescent from an affected family has inherited the disorder; genetic diagnosis may then be indicated. Because of the very variable phenotypic development, it is often not possible to achieve a reliable diagnosis of classical Marfan syndrome in adults either. It often happens that only some of the symptoms are displayed throughout life. Acute aortic syndrome develops at a mean age of 32 years (6-8). Clinical diagnosis can be helped by using the Ghent nosology (9) (table 2). In this procedure, the clinical presentations are differentially weighted and a diagnostic decision is reached on this basis. There is an international consensus $(10,11)$ that genetic testing (mutation screening) is indicated when the clinical diagnosis is uncertain. MFS1 and MFS2 cannot be clinically distinguished, so that genetic testing is needed to clarify this point.

The fibrillin-1 protein consists of 2871 amino acids and has a repetitive structure of functional motives. By the end of 2007, more than 600 different mutations in this gene had been identified which are associated with disease (12). These are distributed over the whole FBN1 gene. Some of these mutations give rise to a fibrillin-1 protein with modified properties, while others change the available quantity of the protein. The prognosis is influenced by the type and localization of the protein. The family history is inconspicuous in about $25 \%$ of established cases of MFS1. These are new mutations.

\section{MASS syndrome}

The designation MASS syndrome (OMIM 60438) is an acronym for mitral valve prolapse, aortic dilatation, with skeletal and skin involvement. The patients do not fulfill the clinical criteria for Marfan syndrome, but exhibit at least mitral valve prolapse. In some patients this syndrome is caused, as in MFS1, by mutations in the FBN1 gene, but the cause of the disease is not known for most of these patients. Mitral valve prolapse may be a component of the familial mitral valve prolapse syndrome (OMIM 157700), but can also occur in the Ehlers-Danlos syndrome and in osteogenesis imperfecta. 
BOX 2

\section{Fundamental Clinical Facts}

- The Marfan syndrome and Marfan-related syndromes are characterized by the greatly increased risk of potentially fatal dissecting aortic aneurysms and usually by the involvement of other organ systems.

- The clinical presentation of these diseases is extremely variable and the genetic causes are highly heterogenous.

- Early and correct diagnosis is essential for optimal case management, perhaps including elective aortic replacement.

- The diagnosis includes clinical and imaging procedures, careful recording of the family history, and genetic testing.

- The Marfan syndrome and Marfan-related syndromes are diseases which may involve several organ systems and therefore require coordinated medical care from specialists in different areas.

\section{Marfan syndrome type 2}

Marfan syndrome type 2 (MFS2, OMIM 154705) is very similar to classical Marfan syndrome (MFS1) (figure 1). Ectopia lentis has not yet been found in any patient with MFS2. However, this symptom may also be missing in MFS1, so that it is not suitable for differential diagnosis. MFS2 has been mapped onto chromosome section $3 \mathrm{p} 22$. The syndrome is caused by mutations in the gene for transforming growth factor beta receptor 2 (TGFBR2) or, more rarely, of the TGFBRI gene (13-15). Patients have been identified in France, Japan, Germany, and Italy (15). It is not possible to distinguish MFS2 from MFS1 with clinical genetic testing, but only by performing a molecular genetic analysis. This differentiation is nevertheless of great importance. It is thought that $T G F B R$ mutations may be associated with an aggressive clinical course, due to vascular complications. This is accompanied by earlier aortic dissection.

\section{Weil-Marchesani syndrome}

The phenotypic presentation of the Weil-Marchesani syndrome (WMS, OMIM 608328) may be regarded as the opposite of MFS1 and MFS2. The patients are rather small. They have short fingers and suffer from stiff joints. However, they share ectopia lentis with MFS1. Like MFS1, WMS is caused by mutations in the FBN1 gene. Aside from the autosomal dominant form, there is also an autosomal recessive form of WMS (OMIM 277600), caused by mutations in the ADAMTS10 gene.

\section{Congenital contractural arachnodactyly}

Congenital contractural arachnodactyly (CCA, OMIM 121050) resembles MFS clinically, but is accompanied

\section{TABLE 1}

\section{Clinical characteristics of different syndromes}

\begin{tabular}{|c|c|c|c|c|c|}
\hline & \multicolumn{2}{|c|}{ Marfan syndrome } & \multicolumn{2}{|c|}{$\begin{array}{l}\text { Loeys-Dietz } \\
\text { syndrome }\end{array}$} & \multirow[t]{2}{*}{ SGS } \\
\hline & Type 1 & Type 2 & Type 1 & Type 2 & \\
\hline Craniosynostosis & & & $(+)$ & & + \\
\hline Hydrocephalus & & & $(+)$ & & $(+)$ \\
\hline Chiari type 1 malformation & & & $(+)$ & & $(+)$ \\
\hline Delayed development & & & $(+)$ & & + \\
\hline Ectopia lentis & + & & & & \\
\hline Hypertelorism & & & + & & + \\
\hline Blue sclera & & & $(+)$ & & \\
\hline Cleft palate/cleft uvula & & & + & & \\
\hline Aortic aneurysm & + & + & + & + & $(+)$ \\
\hline Aneurysms of other arteries & & & + & + & \\
\hline Arterial tortuosity & & & + & + & \\
\hline Persistent ductus arteriosus & & & $(+)$ & & \\
\hline Atrial septum defect & & & $(+)$ & & \\
\hline Dolichostenomelia ${ }^{* 1}$ & + & + & $(+)$ & & + \\
\hline Arachnodactyly & + & + & + & & + \\
\hline Camptodactyly ${ }^{* 2}$ & $(+)$ & $(+)$ & $(+)$ & & $(+)$ \\
\hline Chest malformation & + & + & + & & + \\
\hline Scoliosis & + & $(+)$ & + & & $(+)$ \\
\hline Joint hypermobility & + & + & + & + & + \\
\hline Club foot & & & $(+)$ & & + \\
\hline Striae & $(+)$ & $(+)$ & & & \\
\hline Velvety fragile skin & & & $(+)$ & + & \\
\hline Atrophic scars & & & & + & \\
\hline Hyperelastic skin & & & & $(+)$ & \\
\hline Uterus rupture & & & & $(+)$ & \\
\hline Intestinal or spleen rupture & & & & $(+)$ & \\
\hline Lumbosacral dural ectasia & + & $?$ & $?$ & $?$ & $?$ \\
\hline
\end{tabular}

+ , in $\geq 50 \%$ of patients;

$(+)$, in $<50 \%$ of patients;

?, frequency unknown

*1, long extremities in comparison to trunk;

${ }^{\star 2}$, flexion contracture of the fingers;

SGS, Shprintzen-Goldberg syndrome.

by characteristic joint contractions and often a deformity of the auricles ("crumpled ears"). CCA is caused by mutations in the fibrillin-2 gene (FBN2).

\section{Loeys-Dietz syndrome type 1}

This syndrome was first described in 2005 (16) (LDS1, OMIM 609192), but is probably identical to the Furlong syndrome (OMIM 610168), which has been known since 1987. As can be seen in table 1, almost all symptoms of the classical Marfan syndrome can also be found in LDS1. In addition, the patients suffer from 


\section{TABLE 2}

Checklist for the clinical diagnosis of the Marfan syndrome using Ghentnosology (taken from [10])

\begin{tabular}{|c|c|c|}
\hline Manifestations in the major criterion & Manifestations in the minor criterion & Diagnosis (definition) \\
\hline \multicolumn{3}{|l|}{ Skeleton } \\
\hline Pigeon breast & Funnel chest, mild & $\begin{array}{l}\text { Major criterion fulfilled ( } \geq 4 \text { manifestations } \\
\text { in the major criterion) }\end{array}$ \\
\hline Funnel chest, requiring surgery & Hypermobile joints & $\begin{array}{l}\text { Skeletal involvement ( } 2 \text { manifestations in the } \\
\text { major criterion or } 1 \text { manifestation in the } \\
\text { major criterion and } 2 \text { in the minor criterion) }\end{array}$ \\
\hline $\begin{array}{l}\text { Ratio of arm span to height }>1.05 \text { and/or } \\
\text { upper length to lower length }<0.85\end{array}$ & $\begin{array}{l}\text { High (gothic) palate with malposition } \\
\text { of the teeth due to restricted space }\end{array}$ & \\
\hline Positive wrist and thumb sign ${ }^{\star 1}$ & $\begin{array}{l}\text { Physiognomy ( } \geq 2 \text { ): } \\
\text { - Dolichocephaly (long skull) } \\
\text { - Malarhypoplasia } \\
\text { - Enophthalmos } \\
\text { - Retrognathy } \\
\text { - Lid axis laterally displaced }\end{array}$ & \\
\hline \multicolumn{3}{|l|}{$\begin{array}{l}\text { Club foot from medial displacement } \\
\text { of the inside ankle }\end{array}$} \\
\hline \multicolumn{3}{|l|}{ Scoliosis $>20^{\circ}$ or slipping of a vertebra } \\
\hline \multicolumn{3}{|l|}{ Extensibility of elbow joint $<170^{\circ}$} \\
\hline \multicolumn{3}{|l|}{ Protrusio acetabuli (radiological) } \\
\hline \multicolumn{3}{|l|}{ Eye } \\
\hline \multirow[t]{3}{*}{ Lens luxation or subluxation } & Cornea abnormally flat & Major criterion fulfilled \\
\hline & Eyeball with axial length $>23.5 \mathrm{~mm}$ & $\begin{array}{l}\text { Eye involvement ( } \geq 2 \text { manifestations } \\
\text { in the minor criterion) }\end{array}$ \\
\hline & $\begin{array}{l}\text { Iris/ciliary muscle hypoplastic with } \\
\text { restricted miosis }\end{array}$ & \\
\hline \multicolumn{3}{|l|}{ Cardiovascular system } \\
\hline $\begin{array}{l}\text { Aneurysm of the ascending aorta, } \\
\text { affecting at least the sinus }\end{array}$ & $\begin{array}{l}\text { Mitral valve prolapse, independent of } \\
\text { mitral valve insufficiency }\end{array}$ & Major criterion fulfilled \\
\hline \multirow[t]{3}{*}{ Dissection of the ascending aorta } & $\begin{array}{l}\text { Pulmonary artery dilatation, aged under } 40 \\
\text { (after exclusion of pulmonary valve stenosis) }\end{array}$ & $\begin{array}{l}\text { Cardiovascular involvement ( } \geq 1 \text { manifestation } \\
\text { in the minor criterion) }\end{array}$ \\
\hline & Mitral valve calcification, aged under 40 & \\
\hline & $\begin{array}{l}\text { Dilation or dissection of the descending or } \\
\text { abdominal aorta, aged under } 50\end{array}$ & \\
\hline \multicolumn{3}{|l|}{ Lung } \\
\hline & Spontaneous pneumothorax & $\begin{array}{l}\text { Cardiovascular involvement ( } \geq 1 \text { manifestation } \\
\text { in the minor criterion) }\end{array}$ \\
\hline & Apical blebs (X-rays) & \\
\hline \multicolumn{3}{|l|}{ Skin } \\
\hline & Striae distensae & \multirow{2}{*}{$\begin{array}{l}\text { Skin involvement ( } \geq 1 \text { manifestation in the } \\
\text { minor criterion) }\end{array}$} \\
\hline & $\begin{array}{l}\text { Recurrent hernias or postoperative } \\
\text { hernias }\end{array}$ & \\
\hline \multicolumn{3}{|l|}{ Dura } \\
\hline Lumbosacral dural ectasia & & Major criterion fulfilled \\
\hline \multicolumn{3}{|l|}{ Family history/genetics } \\
\hline First degree relatives with MFS & & Major criterion fulfilled $(\geq 1)$ \\
\hline \multicolumn{3}{|l|}{ FBN1 mutation relevant to disease } \\
\hline Linked haplotype demonstrated & & \\
\hline
\end{tabular}

*1 Positive wrist sign: one wrist can be grasped with the thumb and little finger of the other hand in such a way that the body of the thumb overlaps the finger nail of the little finger: positive thumb sign: the body of the thumb protrudes from the lateral edge of the hand when the thumb is laid in the palm and the fist is closed (figure 1). 

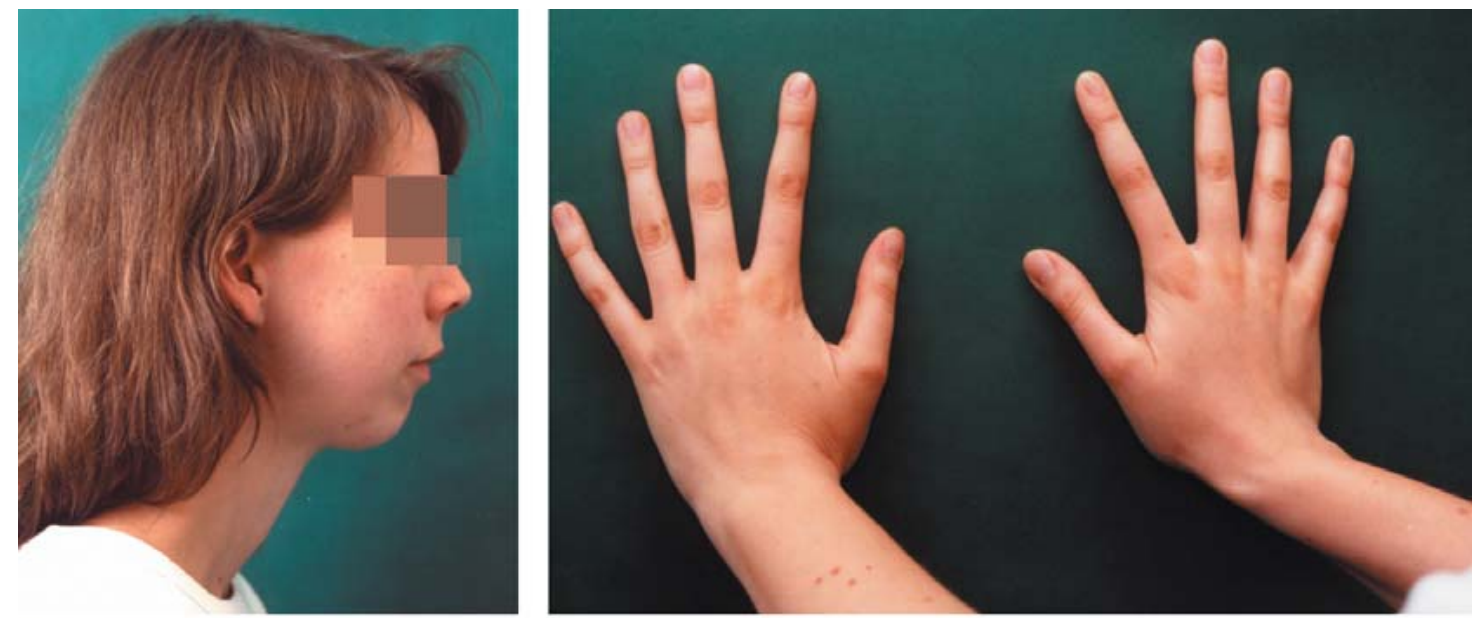

Figure 1:

Patient with Marfan syndrome type 2: arachnodactyly, positive thumb and wrist signs, no cleft uvula, as occurs in LDS1
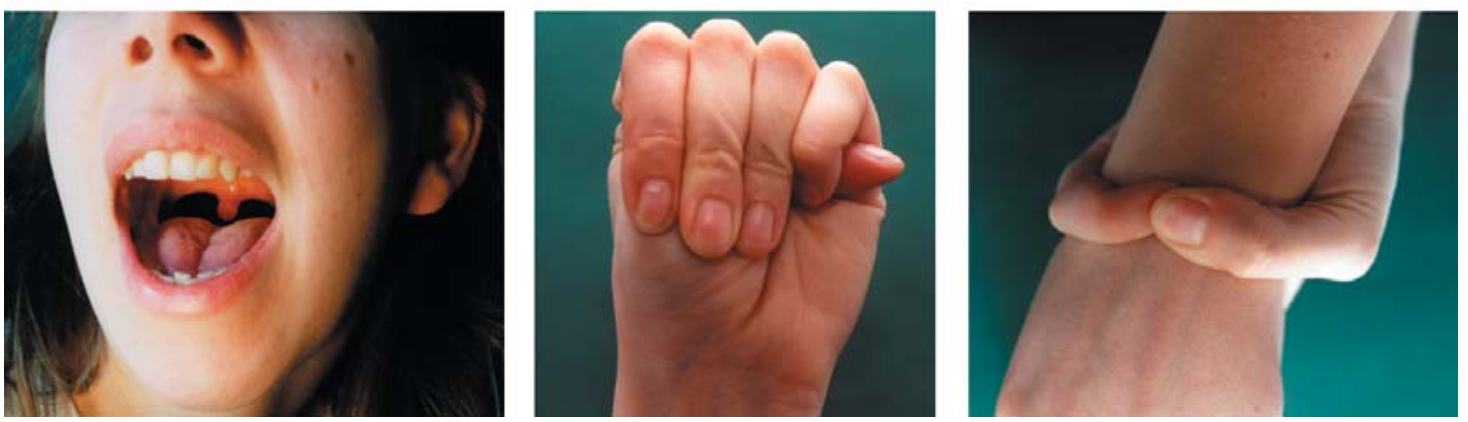

craniofacial malformations (cleft palate or cleft uvula, hypertelorism) and particularly from vascular changes, extending to dilatation, aneurysm formation, and dissection throughout the arterial system. Like MFS2, LDS 1 is caused by mutations in genes TGFBRI (on chromosome 9q33-q34) and TGFBR2 (on chromosome $3 \mathrm{p} 22$ ). The gene products play a decisive role in intracellular transduction of TGF-beta signals. It is known from animal models for mitral valve prolapse and pulmonary symptoms that these signals are important for the development of the vascular system and of the visceral cranium $(17,18)$. The developmental disturbances in the vascular walls are evident in even very young patients. This may explain why complications often develop so early. The mean age for surgical vascular replacement is 16.9 years (19).

\section{Loeys-Dietz syndrome type 2}

The symptoms of Loeys-Dietz syndrome type 1 (LDS1) overlap with the vascular type of the EhlersDanlos syndrome (EDS type 4, EDS4, OMIM 130050). EDS4 is often caused by mutations in the collagen type 3 gene. Loeys et al. (19) investigated 40 patients with the clinical presentation of EDS4, but without collagen type 3 disturbances or craniofacial malformation. In 12 patients, they identified mutations in one of the TGFBR genes. These patients are now assigned to the Loeys-Dietz syndrome type 2 (LDS2, OMIM number not yet allocated). As with LDS1, LDS2 patients suffer from aggressive arterial

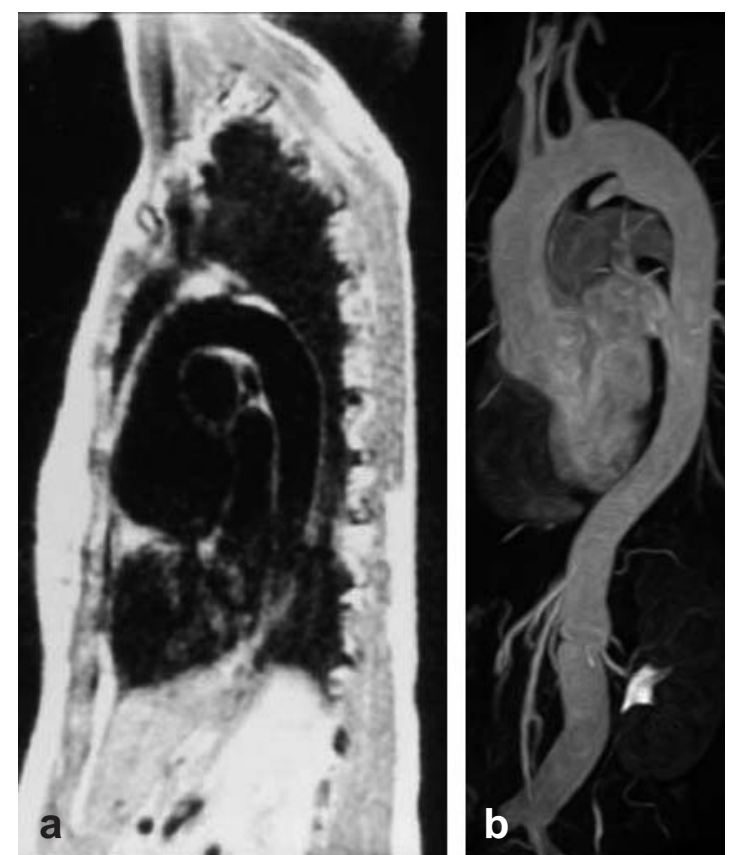

Figure 2: Comparison between the aortic pathology in classical Marfan syndrome (MFS1) with the aorta changes in Loeys-Dietz syndrome type 2 (LSD2). a) Onion shaped aneurysm of the aortic sinus extending to the ascending aorta, typical aorta change in MFS1. b) Example of aortic disease in LDS2 affecting several stages, with ectasia of the aortic root, dilatation of the descending aorta, distally partially open ductus arteriosus and tube prosthesis after implantation of an infrarenal abdominal aorta aneurysm with marked aortic kinking. 


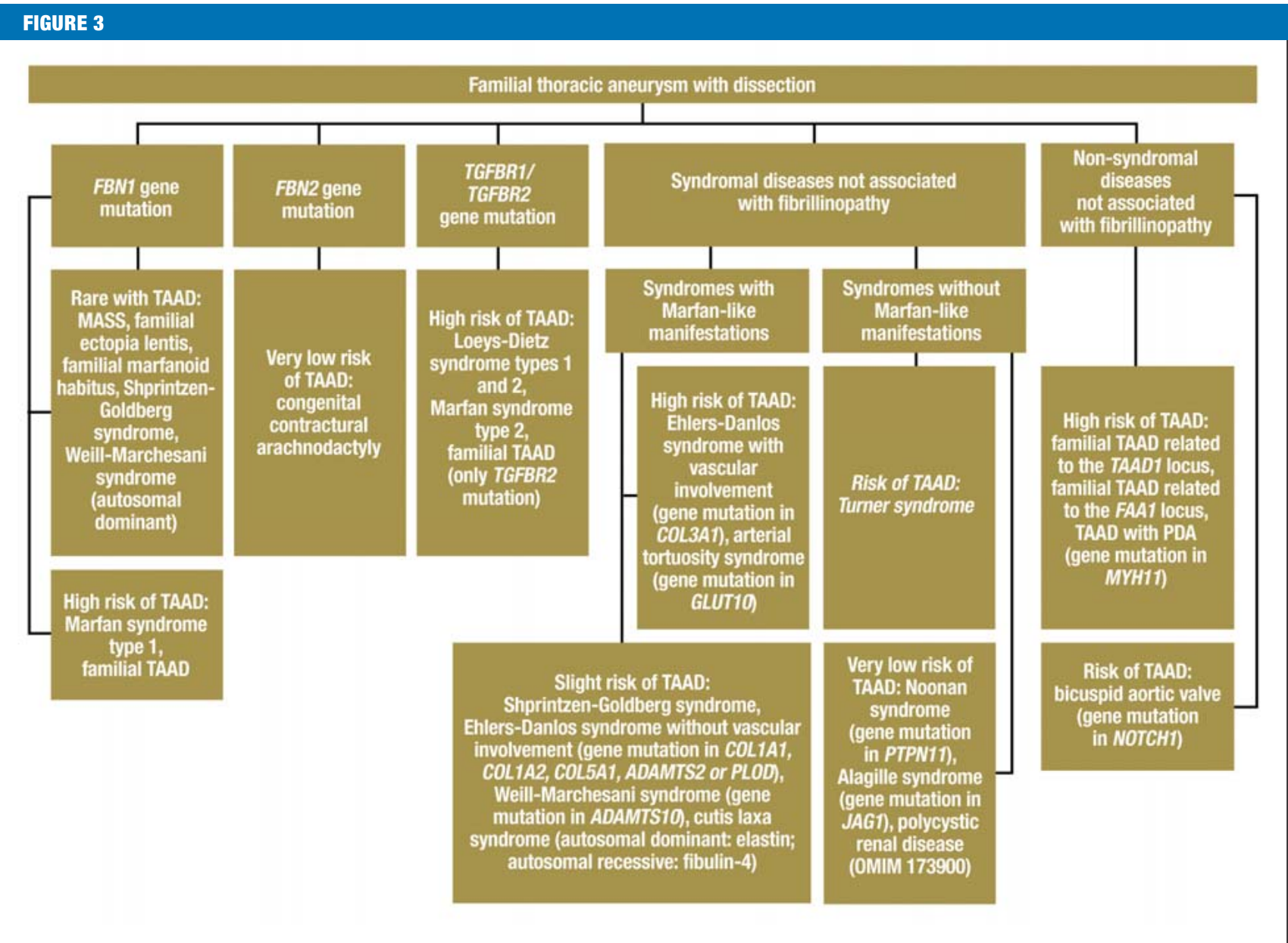

Algorithm for the clinical molecular differential diagnosis of congenital aortic diseases. OMIM: online Mendelian inheritance in man; PDA, persistent ductus arteriosus; TAAD, thoracic aortic aneurysm with dissection 


\section{BOX 3}

\section{Principles of the medical management of Marfan syndrome (23)}

\section{General measures for adults with Marfan syndrome}

- Moderate restrictions to physical activity

- Annual echocardiography and MR angiography of the aorta

- Beta-blockers for aorta protection

\section{Measures if children wanted or in pregnancy}

- Information on the $50 \%$ risk of passing the Marfan syndrome on to children

- High risk pregnancy if aortic root diameter $>40 \mathrm{~mm}$ or after cardiac surgery or in women with severe heart disease

- Prophylactic reconstructive replacement of aortic root for female patients with aortic root diameter of at least $40 \mathrm{~mm}$ who plan pregnancy

- Serial (e.g. every 3 months) echocardiographic follow-ups till 3 months after birth

Indication for prophylactic replacement of the aortic root for adults (at least one criterion)

- Aortic root diameter $>43 \mathrm{~mm}$ (40 mm according to other authors) or aortic quotient $>1.3$

- Aortic root diameter $>40 \mathrm{~mm}$ if there is at least one of the following risk factors:

- Family history of aortic dissection or aortic rupture

- Aortic root diameter increases by more than $10 \mathrm{~mm}$ per year

- Dilatation of the sinus extending to the ascending aorta

- Aortic valve insufficiency of at least intermediate severity
- High grade mitral valve insufficiency

- Planning of a major non-cardiovascular operation

- Women before a planned pregnancy

Indication for prophylactic aortic root replacement in children

- The operation should be after growth is complete, if at all possible.

- The evaluation of the aortic root diameter is orientated on the criteria for adults.

- If the aortic root diameter has been above the upper confidence interval for years and suddenly increases during the echocardiographic controls

\section{Indication for mitral valve surgery}

- The indication is made in accordance with the general recommendations of the American Heart Association.

\section{Endocarditis prophylaxis}

- The current recommendations of the American Heart Association are taken as the minimal standard. The American Heart Association recommends endocarditis prophylaxis only for patients with prosthetic valve replacement, after recovery from endocarditis or for valvulopathy after heart transplantation. As however the risk of endocarditis is generally thought to be very high for Marfan patients, the Professional Advisory Board of the American National Marfan Foundation recommends endocarditis prophylaxis for patients with dysfunctional native heart valves too. 
aneurysms. The mean age for vascular replacement is 26.9 years. Figure 2 shows the differences between MFS1 and LDS2 with respect to vascular pathology.

\section{Shprintzen-Goldberg syndrome}

The Shprintzen-Goldberg syndrome (SGS, OMIM 182212) exhibits common features with both MFS1 and MFS2, as well as with LDS1 (or the Furlong syndrome) and LDS2 (table 1). The most striking feature of SGS is cranial synostosis, which does not occur in MFS1 or MFS2, but does occur in LDS1. No mutations have been found in any of the TGFBR genes in SGS, although there are mutations in FBN1. These clinical findings indicate that there is a connection between fibrillin deficiency and disturbances in the TGFB signal cascade. This could open specific therapeutic options (20).

\section{Familial thoracic aortic aneurysm}

Just as with mitral valve prolapse, aortic aneurysm may either by a component of a syndrome or may be inherited separately (OMIM 607086). Both the syndromal and familial forms are histologically linked to ErdheimGsell cystic medial necrosis, with loss of elastic fibers, deposition of material resembling mucopolysaccharides and cystic changes in the medial aortic wall. Five responsible chromosome regions have been identified (AAT1 to AAT5). AAT3 can be caused by mutations in the TGFBR2 gene, AAT4 by mutations in the gene for myosin heavy chain 11 (MYH11) and AAT5 by changes in the TGFBRl gene. The underlying genes are not yet known for AAT1 and AAT2. Familial thoracic aortic aneurysm with dissection (TAAD) can also be caused by mutations in the ACTA2 gene (21). It has long been known that a bicuspid aortic valve (BAV) is often associated with cystic medial necrosis and the risk of an acute aortic syndrome. Familial forms of the BAV may be caused by mutations in the NOTCHI gene (OMIM 190198). It has become increasingly important for the prognosis and treatment of these syndromes to identify the genetic causes of aneurysm formation. This will be discussed in the examples below.

\section{Clinical management}

Progress in recognizing new syndromes and new molecular causes, together with improved allocation to the syndromes, as discussed above, has led to a totally new concept of clinical management. The fundamental question is whether allocation to a syndrome for aortic disease can be used for a precise estimation of risk, and thus for individual medical care.

As one example, mutation diagnosis can exclude Loeys-Dietz syndrome types 1 and 2 by detecting an FBN1 mutation. However, Marfan syndrome type 1 can only be diagnosed once the clinical criteria of the Ghent nosology have been fulfilled. If these criteria are not fulfilled, the patient may exhibit the MASS phenotype, the Shprintzen-Goldberg syndrome, the Weill-Marchesani syndrome, familial thoracic aortic aneurysm, or familial thoracic aortic dissection. Further differential diagnosis must then be based on clinical criteria. If, on the other hand, mutation diagnosis shows that there is no mutation in the FBN1 gene, but a mutation in the TGFBRl gene, the patient may exhibit Marfan syndrome type 2, or Loeys-Dietz syndrome types 1 or 2 . The distinction between Marfan syndrome type 2 and one of the LoeysDietz syndromes can only be made on a clinical basis. The consequences for treatment depend on the diagnosis (9). Figure 3 shows the algorithm for the differential diagnosis of congenital aortic diseases, based on a combination of molecular and clinical information.

The correct diagnosis is only possible by combining clinical and molecular analysis and then leads to improvements in the assessment of prognosis and in the prophylactic measures taken. Current data indicate that the localization and type of mutation in the FBN1 gene may be associated with specific prognostic characteristics (22). Depending on the risk of the development of the acute aortic syndrome, upper individual limits are set for sport and everyday activities, the intervals for imaging follow-ups and the dosage of drugs to protect the aorta are adjusted, and the indication for prophylactic aortic replacement may be modified. Because of the rarity of the different syndromes, there have not yet been any extensive controlled studies on their medical management. Box 3 gives an overview of the principles for treating the Marfan syndrome.

\section{Interdisciplinary care}

Diseases involving several organ systems require coordinated medical care from different specialities. The optimal situation is when the patient receives interdisciplinary care and all findings and reports on treatment strategies are recorded centrally. The experience of affected patients has been that this rarely happens in Germany (www.marfanhilfe.de). There are complaints of ignorance of the Marfan syndrome and that specialists exclusively concentrate on their own areas (boxes 1 and 2). The patient should always carry an emergency pass with him. If the patient is admitted to hospital as an emergency after acute aortic dissection, the intense sudden chest pain will not be misinterpreted as a myocardial infarction if he has a Marfan emergency pass. If the patient has a dental operation, antibiotic prophylaxis for endocarditis may not be forgotten. If a pregnant woman with Marfan syndrome is to give birth, the obstetrician can plan the proper mode of birth in good time. The objective must be to achieve early diagnosis, to allow the initiation of preventive measures and punctual and regular follow-ups in good time. Medical treatment can be optimized by avoiding complications and emergency operations, thus improving the clinical course and increasing life expectancy.

Dedicated to Professor Hans Georg Borst on the occasion of his 80th birthday.

\section{Conflict of interest statement}

The authors declare that no conflict of interest exists according to the guidelines of the International Committee of Medical Journal Editors.

Manuscript received on 5 0ctober 2007, revised version accepted on 21 February 2008.

Translated from the original German by Rodney A. Yeates, M.A., Ph.D. 


\section{REFERENCES}

1. Management of genetic syndromes, 2nd edition. Cassidy SB, Allanson JE (Hrsg.) Hoboken: Wiley-Liss 2005.

2. von Kodolitsch Y, Baumgart D, Eggebrecht $H$ et al.: Das akute Aortensyndrom. Dtsch Arztebl 2003; 100(6):A 326-33.

3. Silvermann DI, Burton KJ, Gray J et al: Life expectancy in the Marfan syndrome. Am J Cardiol 1995; 75: 157-60.

4. Orphanet-Handbuch Seltene Erkrankungen. Neu-Isenburg: MMIVerlag 2007.

5. WHO report on priority medicines for europe and the world. World Health Organization. WHO document WHO/EDM/PAR/2004.7. Geneva 2004.

6. von Kodolitsch Y, Kuhnel P, Kreymann G, Nienaber CA: Lysis therapy in aortic dissection: by hypertrophic cardiomyopathy simulated myocardial infarct. Z Kardiol 1998; 87: 150-60.

7. von Kodolitsch Y, Rybczynski M: Cardiovascular aspects of the Marfan syndrome - A systematic review. In: Marfan syndrome: a primer for clinicians and scientists. Robinson PN, Godfrey M (Hrsg.) Hingham, MA, USA: Kluwer Academic/Plenum Publishers, 2004; 45-69.

8. von Kodolitsch Y, Robinson PN: Marfan syndrome. An update of genetics, medical and surgical management. Heart 2007; 93: 755-60.

9. De Paepe A, Devereux RB, Dietz HC, Hennekam RCM, Pyeritz RE: Revised diagnostic criteria for the Marfan syndrome. Am J Med Genet 1996; 62: 417-26.

10. De Backer J, Loeys B, Leroy B, Coucke P, Dietz H, de Paepe A: Utility of molecular analyses in the exploration of extreme intrafamilial variability in the Marfan syndrome. Clin Genet 2007; 72: 188-98.

11. Faivre L, Collod-Beroud G, Loeys BL et al.: Contribution of molecular analyses in diagnosing Marfan syndrome and type I fibrillinopathies: an international study of 1009 probands. J Med Genet 2008; Feb 29 [Epub ahead of print]

12. The FBN1 mutations database www.umd.be:2030

13. Matyas G, Arnold E, Carrel T et al.: Identification and in silico analyses of novel TGFBR1 and TGFBR2 mutations in Marfan syndrome-related disorders. Hum Mutat 2006; 27: 760-9.
14. Singh KK, Rommel K, Mishra A et al.: TGFBR1 and TGFBR2 mutations in patients with features of Marfan syndrome and LoeysDietz syndrome. Hum Mutat 2006; 27: 770-7.

15. Mizuguchi T, Collod-Beroud G, Akiyama T et al.: Heterozygous TGFBR2 mutations in Marfan syndrome. Nat Genet 2004; 36: 855-60.

16. Loeys BL, Chen J, Neptune ER, et al.: A syndrome of altered cardiovascular, craniofacial, neurocognitive and skeletal development caused by mutations in TGFBR1 or TGFBR2. Nat Genet 2005; 37: 275-81.

17. Neptune ER, Frischmeyer PA, Arking DE et al.: Dysregulation of TGFbeta activation contributes to pathogenesis in Marfan syndrome. Nature Genet 2003; 33: 407-11.

18. Ng CM, Cheng A, Myers LA et al.: TGF-beta-dependent pathogenesis of mitral valve prolapse in a mouse model of Marfan syndrome. J Clin Invest 2004; 114: 1586-92.

19. Loeys BL, Schwarze U, Holm T: Aneurysm syndromes caused by mutations in the TGF-beta receptor. N Engl J Med 2006; 355: 788-98.

20. Judge DP, Dietz HC: Therapy of Marfan Syndrome. Annu Rev Med 2007; 59: 43-59.

21. Guo DC, Pannu H, Tran-Fadulu V et al.: Mutations in smooth muscle alpha-actin (ACTA2) lead to thoracic aortic aneurysms and dissections. Nat Genet 2007; 39: 1488-93.

22. Faivre L, Collod-Beroud G, Loeys BL et al.: Effect of mutation type and location on clinical outcome in 1,013 probands with Marfan syndrome or related phenotypes and FBN1 mutations: an international study. Am J Hum Genet 2007; 81: 454-66.

23. von Kodolitsch Y, Rybczynski M, Detter C, Robinson PN: Diagnosis and management of Marfan syndrome. Future Cardiology 2008; 4: 85-96.

\section{Corresponding author}

Prof. Dr. med. Jörg Schmidtke

Institut für Humangenetik

Medizinische Hochschule Hannover

Carl-Neuberg-Str. 1, 30625 Hannover, Germany

schmidtke.joerg@mh-hannover.de 